
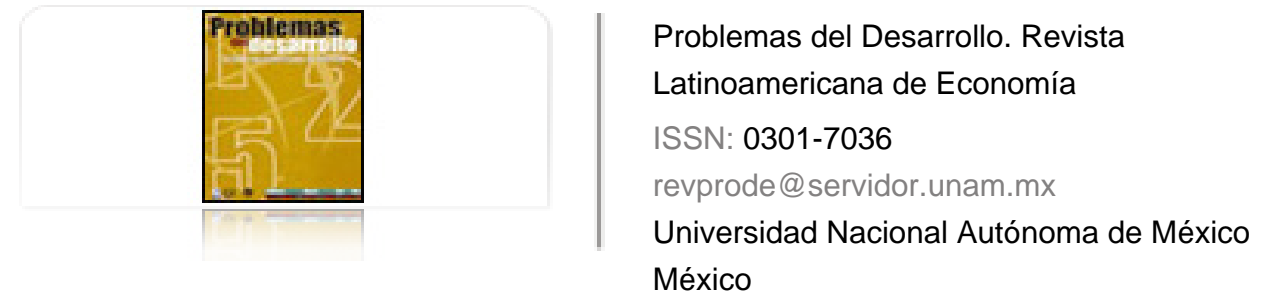

Vargas Hernández, José Gpe.

La nueva economía política en la transformación institucional del Estado-Nación Problemas del Desarrollo. Revista Latinoamericana de Economía, vol. 37, núm. 145, abril-junio, 2006 , pp. 31-51

Universidad Nacional Autónoma de México

Distrito Federal, México

Disponible en: http://www.redalyc.org/articulo.oa?id=11820086003

Cómo citar el artículo

- Número completo

- Más información del artículo

Página de la revista en redalyc.org

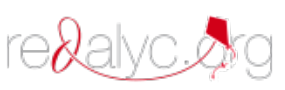

Sistema de Información Científica

Red de Revistas Científicas de América Latina, el Caribe, España y Portugal Proyecto académico sin fines de lucro, desarrollado bajo la iniciativa de acceso abierto 


\section{LA NUEVA ECONOMÍA POLITICA EN LA TRANSFORMACIÓN INSTITUCIONAL DEL ESTADO-NACIÓN}

\section{José Gpe.Vargas Hernández*}

Fecha de recepción: 16 de diciembre de 2004. Fecha de aceptación: 15 de marzo de 2006.

\section{Resumen}

El propósito de este trabajo es analizar la racionalidad instrumental de la nueva economía politica en la transformación institucional del Estado, a partir de un enfoque conceptual y metodológico transdisciplinario del desarrollo, el cual implica la interacción de lo económico y lo político. La racionalidad se analiza desde sus componentes individual y social para desprender sus implicaciones en la teoría de la acción colectiva y en la racionalidad económica de las decisiones. Se hace especial énfasis en la implantación de los principios del neoinstitucionalismo y la nueva economía política, que proporcionan los fundamentos teórico-metodológicos y el instrumental necesario para los procesos de cambio y transformación institucional del Estado.

Palabras clave: racionalidad instrumental, neoinstitucionalismo, nueva economía politica, transformación institucional, Estado-nación.

\section{Abstract}

The aim of this study is to analyze the instrumental rationality of the new political economy in the institutional transformation of the State, based on an interdisciplinary conceptual and a methodological focus on development, which implies the interaction of the economic and the political. Rationality is analyzed from its individual and social components to separate its implications for the theory of collective action and for the economic rationality of decisionmaking. Special emphasis is put on the implementation of the principles of neo-institutionalism and the new political economy, which provide the theoretical-methodological and instrumental bases necessary for the processes of change and institutional transformation of the State.

Key words: instrumental rationality, neo-institutionalism, new political economy, institutional transformation, nation-state.

* Profesor investigador del Instituto Tecnológico de Cd. Guzmán. Correo electrónico: jgvh0811@yahoo.com 


\section{Résumé}

Le but de ce travail c'est d'analyser la rationalité instrumentale de la nouvelle économie politique dans la transformation institutionnelle de l'Etat, à partir d'un point de vue conceptuel et méthodologique transdisciplinaire du développement qui implique l'interaction des domaines économique et politique. La rationalité est analysée depuis ses composantes individuelle et sociale pour en détacher ses implications dans la théorie de l'action collective et dans la rationalité économique des décisions. On met l'accent sur l'implantation des principes du néoinstitutionnalisme et la nouvelle économie politique qui fournissent les fondements théorico-méthodologiques ainsi que l'instrument nécessaire pour les processus de changement et de transformation institutionnel de l'Etat

Mots-cléfs: rationalité instrumentale, néoinstitutionnalisme, nouvelle économie politique, transformation institutionnelle, Etat-nation.

\section{Resumo}

O objetivo deste trabalho é analizarmos a racionalidade instrumental da nova economia politica na transformação institucional do Estado, desde uma visão conceptual e metodológica transdisciplinária do desenvolvimento, o que envolve a interação do político e o econômico. A racionalidade analiza-se desde os seus componentes tanto individual quanto social para desprender suas implicações na teoria da ação coletiva e na racionalidade econômica das decisões. Se dá maior ênfase na implantação dos princípios do neoinstitucionalismo e a nova economia política, que fornecem os fundamentos teórico-metodológicos e as ferramentas necesárias para os processos de mudança e transformação institucional do Estado.

Palavras chave: racionalidade instrumental, neoinstitucionalismo, nova economia política, transformação institucional, Estado-nação.

\section{DeSarrollo}




\section{Introducción}

ara el estudio de los cambios en la economía global y sus consecuencias en el
desarrollo, de acuerdo con Appelbaum y Henderson (1995), es necesario un enfoque
conceptual y metodológico transdisciplinario que vaya más allá de las especializaciones intelectuales tales como la economía de los negocios, la economía política, la sociología organizacional, la geografía económica, las relaciones internacionales y los estudios del desarrollo.

En otras palabras, para analizar los fenómenos del desarrollo en el ambiente de los procesos de globalización, se requiere también de marcos teórico-metodológicos más integradores, totalizadores, de visión más holista. Ese enfoque permite mantener una visión plural dimensional y analógica de la realidad de los fenómenos objeto de estudio; de una realidad que se está convirtiendo en hiperrealidad y que modifica nuestras interpretaciones fundamentadas en estructuras piramidales y las lleva a estructuras de relaciones más planas.

La forma de acercarse al análisis del fenómeno del desarrollo en la era de la globalización es por medio de una perspectiva que implique la interacción de lo económico y lo político. La cientificidad de una ciencia sólo es cuestionable a partir de la ciencia misma, pero su modo de existir y de funcionar se cuestiona por la práctica política. La economía política intenta conectar el análisis económico con la práctica política para analizar los problemas relacionados con el desarrollo mediante el estudio de los procesos sociales institucionales de los grupos económicos y políticos y sus decisiones de elección, regulación y poder que influyen en la asignación de los recursos.

\section{Economía política}

Los diferentes enfoques a la economía política abarcan desde el que considera al individuo que actúa racionalmente como unidad de análisis hasta el enfoque de racionalidad social. La economía política racional se centra en el estudio de los intereses como productores de una dialéctica de la racionalidad e irracionalidad. Al considerar al individuo como la unidad de análisis, no toma en cuenta las estructuras e interacciones de los agrupamientos humanos y su influencia en el desarrollo. La cultura intelectual racionalista y científica encuentra sus limitaciones en las manifestaciones de la pluralidad de la acción colectiva.

Desde la perspectiva de la elección racional, el tema del desarrollo visto por la economía política trata de la forma en que los actores realizan en los mercados conductas estratégicas de elección y razonamiento para maximizar intereses propios que persiguen en función de incentivos, así como de los problemas de agregación mediante la teoría de la acción colectiva 
y de la acción democrática. El mito de la obtención del máximo beneficio del mercado desencadena una tendencia perversa que sobrepone la utilidad económica a los valores sociales, culturales y políticos.

Desde esta perspectiva, el desarrollo orientado por la racionalidad instrumental se empantana cuando se intenta alcanzar objetivos de bienestar social. La racionalidad instrumental de la nueva economía política requiere de una reformulación teóricometodológica que trascienda la racionalidad instrumental para dar un nuevo cauce al desarrollo. Este trabajo pretende analizar la racionalidad instrumental de la nueva economía política en la transformación institucional del Estado, a partir de un enfoque conceptual y metodológico transdisciplinario del desarrollo que implica la interacción de lo económico y lo político.

\section{Enfoque racionalista-individualista}

La elección racional (rational choice) como cuerpo teórico para explicar el comportamiento humano implicado en el desarrollo, desplaza los planteamientos basados en las normas y papeles sociales transmitidos por los mecanismos de socialización y la tradición. En cuanto método, el enfoque racionalista acepta el individualismo y se fundamenta en el principio de que los individuos (unidad de análisis) son autointeresados, es decir, orientados a la satisfacción de sus propios intereses, deseos y actividades determinados material y políticamente.

Así, la economía política racional se centra en el estudio de los intereses como productores de una dialéctica de la racionalidad e irracionalidad. Al considerar al individuo como la unidad de análisis, no toma en cuenta las estructuras e interacciones de los agrupamientos humanos y su influjo en el desarrollo. Los individuos maximizan sus utilidades en una forma racionalmente perfecta mediante la previsión de todos los posibles resultados, la determinación de los diferentes cursos de acción y la evaluación de las consecuencias en términos de costos.

Se pueden identificar cuatro tipos de racionalidad: la racionalidad práctica, que calcula en forma pragmática los medios para sortear las dificultades; la racionalidad teórica o construcción de conceptos abstractos precisos como la deducción, atribución de causalidad y la formación de significados simbólicos; la racionalidad sustantiva o preferencia por valores últimos, y la racionalidad formal por el cálculo de medios-fines.

Los conceptos de racionalidad sustantiva y de racionalidad práctica informados por las obligaciones sociales y morales son posibles rutas para incorporar el de valores. Los tipos de racionalidad que informan la acción racional y sus implicaciones en el desarrollo, son la racionalidad sustantiva que informa la acción valoral-racional y la racionalidad formal que informa la acción racional instrumental.

\section{DeSarrollo}


Los tipos de acción social de Weber son el afectivo, basado en la emoción; el tradicional, asentado en el hábito; el valoral-racional (wertrational), cimentado en valores, y la racionalidad medio-fin, fundada en el cálculo. La acción social es racional, apoyada en ideas y elección consciente; las racionalidades afectivas y tradicional, categorizadas por Weber (1978:25) cerca de la frontera que denominó acción orientada; mientras que la racional valoral y la acción racional medios-fines son más reflexivas o autoconscientes.

La racionalidad formal informa la acción racional de la relación medios-fines. Polanyi (1975) define la acción racional como la elección de unos medios en relación con un fin. Es decir, la especificidad de la acción racional no se refiere "ni a los medios ni a los fines, sino a la relación medios-fines". En otras palabras, la especificidad de la acción racional está en la relación elección instrumental (medios) con el desarrollo (fin). La racionalidad sustantiva ordena la acción con relación al valor postulado en el pasado, presente y potencial, o bien, al agrupamiento de valores en el cual la conducta se evalúa por sí misma, independientemente de sus perspectivas de éxito. La racionalidad teórica involucra un dominio consciente de la realidad por medio de la construcción de conceptos abstractos precisos del desarrollo por alcanzar. La racionalidad práctica guía las acciones del desarrollo en rutinas diarias, provee patrones de acción para los medios de trato con las dificultades prácticas inmediatas.

Los supuestos económicos de la elección racional y las implicaciones en el desarrollo de los pueblos que fluyen lógicamente en dichos supuestos, sugieren que es el mercado y no la intervención del Estado, el que asegura la presencia de los términos del contrato que son socialmente eficientes y óptimos para los compradores considerados como una clase. La capacidad para elegir es la base de la sociedad del consumo mediante la expresión de preferencias. La elección racional es un enfoque individualista del desarrollo porque confunde el bienestar con las preferencias y las elecciones.

Habermas (1992:408) puntualiza que la teoría de la elección racional todavía se relaciona con la solución del problema hobbesiano. Los principios que critica son la estabilidad de las preferencias y la conducta de maximización de utilidad. Las preferencias declaradas del individuo no son necesariamente las que tendrían cuando está mejor informado, lo cual prueba que la teoría de la elección racional no es realista o adecuada. Para los expresivistas, la racionalidad es una forma apropiada de manifestación de actitudes y expresiones que no promueven buenos resultados del desarrollo. Para los teóricos de la virtud, la elección racional es la que una persona con ciertos rasgos del carácter, tales como el buen juicio, involucramiento emocional y otros rasgos, escogería. La agregación de elecciones racionales incide directamente en los resultados del proyecto de desarrollo.

Las bases de los principios del homo economicus en una economía política racional no pueden explicar convincentemente la emergencia del orden estable, porque cuando los individuos tienen preferencias firmes no pueden deliberar ni elaborar un discurso. Aunque 
tengan información incompleta de las posibles opciones y de sus diferentes consecuencias del desarrollo, las opciones declaradas no son necesariamente estables. Los cambios en la conducta no se deben a cambios en las preferencias debido a la intensificación del discurso, sino a una información más completa acerca de las implicaciones en el desarrollo. El principio de la estabilidad de las preferencias no origina la posibilidad de que, después del discurso, la gente prefiera opciones diferentes de aquellas que ha declarado.

\section{Enfoque de racionalidad social}

La economía política de la política social es entendida como la intersección de los factores económicos, políticos, sociales y culturales del desarrollo que afectan la racionalidad de las elecciones de la política social. Las interpretaciones racionales de las condiciones económicas de los actores son moderadas por una lógica institucional del más amplio medio ambiente que define las normas, valores y creencias que estructuran la cognición de los actores organizacionales y generan el entendimiento colectivo para formular las decisiones sobre el desarrollo en una racionalidad social de acuerdo con sus intereses.

La racionalización social es un proceso que involucra la emancipación de la tradición y que conduce a la diferenciación de la sociedad en distintas actividades y esferas de valor autónomas y con sus propias normas y obligaciones. Los diferentes estratos sociales tienen procesos de racionalización social específicos y distintos grupos sociales pueden responder en formas diversas a los tipos de racionalidad inherentes a los mitos racionalizados. Éstos tienen diferentes componentes de racionalidad social. Por lo tanto, en esta última, cada esfera de valor tiene patrones de acción y formas de vida que se definen como racionales de aquellas otras esferas consideradas irracionales. Lo anterior determina el concepto de lógica institucional del desarrollo. Por ejemplo, los mitos culturales como un producto de la irracionalidad de las masas son el aglutinante necesario para la cohesión social y la unidad nacional. Sin embargo, hay un lado oscuro en el que la irracionalidad social se convierte en algo más que una profunda negación al servicio de la maldad.

El racionalismo constructivista ilustrado consideraba que la sociedad puede ser objeto de pleno conocimiento y de gobierno perfecto desde la ciencia. Hume planteó que se da valor a la creencia surgida de una reflexión de nuestras percepciones imperfectas de la realidad y a una imaginación socavada por la razón. Los valores sociales limitan la elección racional individual, pero proporcionan nuevas posibilidades para el desarrollo de los pueblos. Los valores sociales compartidos favorecen el sentido de pertenencia, fortalecen la identidad comunitaria, y sustentan el mercado y el Estado como mecanismos de integración, gobernabilidad y ordenamiento social.

La concepción de la racionalidad pública es consecuencialista. En la teoría de la utilidad esperada, a cada resultado se le asigna una utilidad; y para cada opción, en una situación de elección, existe una probabilidad determinada de que se convierta en un producto dado.

\section{DeSRarrollo}


A cada opción puede asignársele una utilidad esperada. Es, por lo tanto, una variante del enfoque consecuencialista de la racionalidad, aunque no es la única posibilidad. Así, por ejemplo, la falta de incentivos adecuados para la participación ciudadana requiere del fortalecimiento del marco institucional del desarrollo. Una vez tomadas las decisiones constitucionales, los costos externos potenciales de los individuos son pequeños, de tal forma que la participación es racional para los grupos de interés organizados. Puede suceder que los ciudadanos convertidos en meros consumidores adquieran la capacidad de ejercitar la elección racional por obra del libre mercado.

En un modelo de economía política es necesario identificar la incidencia distributiva de las propuestas del desarrollo en consideración, pero no en el ámbito de antecedentes de los bienes públicos. No es posible el análisis sin especificar cómo el bien público debe ser financiado. Una base conveniente implica un ajuste de beneficio que absorba impuestos como una distribución financiera neutral. Cuando los bienes públicos son un sustituto perfecto para el consumo privado, la disponibilidad mayor de un bien financiado en una forma de distribución neutral no tiene efectos en la optimación de la distribución. La incidencia distributiva de preexistentes bienes públicos, como productos del desarrollo, es un principio relevante de cuánta redistribución mediante el esquema de la transferencia de impuestos es la mejor, considerando que los bienes públicos afectan los niveles de utilidad de servicios de los individuos y las utilidades de los servicios marginales de consumo. Sin embargo, los datos relevantes relacionados con los niveles de utilidad de los servicios y las utilidades de los servicios marginales sin que se identifiquen, difieren en el nivel prevaleciente de bienes públicos y servicios.

\section{Teoría de la acción colectiva}

Los problemas de esta acción se identifican como dilemas sociales entre la racionalidad individual y la colectiva en situaciones en las cuales la racionalidad individual de los actores queda atrapada para producir resultados no óptimos en términos de bienestar agregado. Existe un problema de acción colectiva cuando la acción individual racional se relaciona con resultados de bienestar inferiores al óptimo de Pareto, el cual es el menos preferido por cada individuo. Los problemas de distribución de los beneficios del desarrollo que implican resultados eficientes y estables resultan en desigualdad en el óptimo de Pareto, lo cual conduce a conflictos manifiestos. El óptimo y subóptimo de Pareto determinan si el resultado de un juego implica conflicto entre las racionalidades colectiva e individual.

El nuevo papel del mercado aglutinado en los crecientes procesos de globalización y de tecnología se centra en sustituir a los ciudadanos por simples consumidores, siempre en función de su capacidad adquisitiva, con lo cual desarticula la acción colectiva y diluye la solidaridad social. En la repetición infinita del "dilema del prisionero", los jugadores no tienen certeza acerca de las preferencias de otros, por lo cual la cooperación es la estrategia

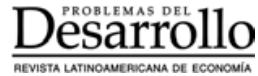


racional. La acción colectiva puede eliminar las restricciones y deficiencias del "dilema del prisionero" si se acuerdan metas en conjunto por todos los miembros de una comunidad. Las soluciones a la teoría de juegos incluyen estrategias mixtas, correlacionadas, secuenciales, interacción repetida, comunicación coordinativa y soluciones de punto focal.

Los diferentes tipos de problemas de acción colectiva, desde la perspectiva de los mecanismos de solución, pueden caer en las categorías de problemas de coordinación y problemas que implican conflictos. Los problemas de coordinación se resuelven mediante una variedad de mecanismos no cooperativos que trabajan en el ámbito individual y se basan en las expectativas racionales. Éstas y las monetaristas son una versión de la economía neoclásica, la cual pone en conflicto a las políticas sociales con las económicas, y por lo mismo, la dinámica del desarrollo se estanca. Gilbert y Michie (1997) concluyen al respecto que los supuestos de clarificación del mercado y de las hipótesis de las expectativas racionales de una economía no pueden desviarse sistemáticamente de su centro de gravedad o del correspondiente nivel de tasa natural de desempleo de los monetaristas. Es decir, sólo existe un único conjunto equilibrado de precios y, por lo tanto, de un nivel correspondiente de empleo y producto.

En lo que respecta al uso de las hipótesis de las expectativas racionales, éstas se consideran un modelo que todos los agentes representativos del desarrollo tienen en sus mentes, en el cual no existen posibilidades de error sistemáticas, a menos que dicho modelo no sea verdadero, y cuya existencia implica una distribución objetiva de eventos futuros. Si la estructura del modelo de desarrollo no es independiente de las expectativas, entonces el modelo verdadero no existe. Por lo mismo, si las expectativas se autocumplen, entonces no existe una distribución objetiva que pueda ser explotada por agentes racionales. En la modelación económica del desarrollo, por ejemplo, la cultura no es relevante porque no es tan obviamente racional. Por ello, no encaja muy bien en la metodología del agente racional de la economía neoclásica (Hermalin, 1999).

Los juegos de coordinación implican el problema de que los actores no sean capaces de coordinar sus estrategias en un equilibrio del desarrollo deseable. La mayor parte de las estrategias individuales basadas en las expectativas racionales trabajan con problemas de coordinación. Sin embargo, éstos también se pueden solucionar mediante mecanismos políticos.

Los problemas que involucran conflicto incluyen el desacuerdo, la distribución, la defección y la inestabilidad, los cuales se solucionan mediante mecanismos colectivos y coercitivos. Los mecanismos colectivos y coercitivos para solucionar problemas de coordinación implican la muerte propia de cada individuo. Aunque no son herramientas necesarias, pueden resolver todos los problemas. Cuando hay muchos jugadores, la regulación jerárquica de la coordinación puede ser eficiente, como en el caso de las reglas de tráfico. En problemas de desacuerdo, puede ser necesario para la comunidad encontrar 
acuerdos autoimpuestos. Sin embargo, en los otros tres tipos de problemas de acción colectiva se necesita la coerción; a pesar de que no siempre es efectiva, complementa los mecanismos políticos, aunque a veces puede reemplazarlos.

Los costos de la acción colectiva de quienes resisten el cambio institucional, como en el caso de los dictadores, hacen que no les resulte racional emprenderlo. En situaciones similares, las soluciones políticas para los problemas de acción colectiva son de procedimiento o institucionales basados en toma de decisiones y coerción colectiva. La propuesta de la teoría política clásica, que no es del todo política, es la solución hobbesiana que delega todos los poderes a un soberano, quien procura, por medio de la coerción, encauzar todas las conductas de los actores en la cooperación, es decir, en la necesidad de tener un poder externo que imponga reglas y exija el cumplimiento de los contratos que solucionen en forma cooperativa los dilemas colectivos.

\section{La racionalidad económica de las decisiones}

Las investigaciones interdisciplinarias (que no son transdisciplinarias) de las ciencias conductuales presentan evidencias sustanciales de que los individuos toman decisiones que se desvían del modelo teórico de la elección racional y de versiones limitadas de la racionalidad como un enfoque que se aproxima a la realidad. Lo anterior como consecuencia de las limitaciones cognitivas para procesar información, determinar los costos de información en relación con los costos de transacción e información de las restricciones ambientales como legales. Coase (1937) introdujo y definió el término costos de transacción como los costos por usar el mercado. Este concepto daría una racionalidad económica a la existencia de las firmas. De la racionalidad económica se deriva la administrativa, que busca la optimación, eficiencia y eficacia de la provisión de bienes públicos en las organizaciones del sector público mediante el empleo de técnicas, métodos e instrumentos gerenciales que se aplican en las organizaciones privadas con fines de lucro.

El concepto de racionalidad económica es más amplio — con un determinado propósito y/o de la relación medio-fin - que el del propio dominio de la racionalidad formal e instrumental. La racionalidad limitada y los costos de transacción positivos están relacionados. En condiciones de incertidumbre, las probabilidades no se atan a un número finito de eventos, como en el caso de situaciones de riesgo en los cuales es posible calcular los valores esperados en el marco de referencia de la teoría de las decisiones. En condiciones de incertidumbre, la racionalidad perfecta tiene poco sentido, por lo que Simon (1955) la denominó "racionalidad limitada".

El concepto de racionalidad perfecta o completa es incompatible con el discurso del desarrollo, debido a las limitaciones de su capacidad para predecir los sucesos y para evaluar los resultados de las diferentes alternativas con el fin de decidir óptimamente en un instante y con los menores costos. Información incompleta, disparidad y división del

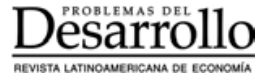


conocimiento disponible requieren de la comunicación para la generación de nuevas ideas. Los actores tienen información incompleta acerca de las diferentes consecuencias de las normas alternativas. La denominada ignorancia racional en economía hace alusión a la participación de los individuos en un discurso sobre el desarrollo en el cual todos los miembros de la sociedad son afectados, pero su impacto en los resultados de las diferentes alternativas es marginal.

Para Habermas (1992), los modos del discurso son pragmáticos, éticos, políticos y morales, totalmente diferentes a las negociaciones, en las cuales las representaciones estratégicas de las preferencias y los rasgos de los participantes son importantes. La racionalidad de las reglas en condiciones de incertidumbre justifica el uso de guías de acción y reglas para determinar la conducta en ciertas situaciones. La teoría económica de la forma de contratos asume un tipo de conducta racional de parte de los agentes económicos del desarrollo denominada teoría de la utilidad esperada. De acuerdo con esta teoría, se plantea que los mencionados agentes económicos usen el mercado para maximizar su utilidad esperada. Este supuesto conductual no parece objetable si se considera que los individuos tienen diferentes metas en un proyecto de desarrollo, pero que todos intentan satisfacerlas en forma tan económica como sea posible, lo que nos lleva a supuestos acerca de las tomas de decisión.

La teoría económica predice formas contractuales que contienen términos eficientes implícitamente, mismos que se fundamentan en supuestos de que los agentes económicos del desarrollo emplean comparaciones de costo-beneficio en forma compensatoria y no selectiva entre todas las posibles alternativas de beneficios que consideran. Aunque con limitaciones cognitivas y restricciones externas en tiempo y esfuerzo, todas las posibles decisiones son elaboradas en un marco de racionalidad. A pesar de que el mercado espera proveer términos contractuales eficientes que den ventajas a todos los agentes económicos, tanto a los compradores como a los vendedores, tales términos no siempre son del todo defendibles.

Las formas de los contratos contienen términos ineficientes porque la conducta racional de toma de decisiones de los agentes económicos previene al mercado de asegurar que se ofrezcan solamente términos eficientes. No resulta tan obvio que den el peor resultado posible en bienestar social y bienestar del agente económico con respecto de las alternativas disponibles.

La evidencia de que la toma de decisiones en función de la elección racional se desvía sistemáticamente de los supuestos de la maximización de la utilidad, el interés propio y la maximización de la riqueza requiere que los consecuentalistas reemplacen sus preferencias por mercados no regulados: teniendo en cuenta que para realizar estos objetivos se necesita desviar ciertas propuestas de competencia institucional referidas a los mercados y a la intervención del gobierno mediante la política económica en el modelo de desarrollo.

\section{DeSarrollo}


El modelo clásico racional de toma de decisiones para el desarrollo, que marca etapas sucesivas claramente distinguibles, es diferente al de interacción estratégica. La teoría de la elección racional es aquella en la cual cada actor tiene control sobre ciertos recursos, intereses y eventos. La existencia de al menos dos actores en el control de recursos es la base del sistema social. En la teoría de las decisiones colectivas de Coleman (1988) se integra lo micro y lo macrosocial sobre la base de la teoría de la elección racional, considerando al capital social como recurso de los actores en forma de obligaciones y expectativas, capacidad de flujo de información de la estructura social y las sanciones de las normas.

Los microsucesos son el modo de acción e interacción subjetiva en la que tanto por rutina y presencia sistémica toma forma la estructura social que institucionalizan los sujetos en la interacción (Giddens 1984:170-173). Así, la formulación de políticas económicas se fundamenta en el equilibrio de la interacción racional de los agentes económicos en los proyectos de desarrollo. La conducta de toma de decisiones es altamente contingente del contexto que hace posible identificar la estrategia específica que el agente económico usa al tomar decisiones de beneficios esperados del desarrollo, o tener una lista precisa de los atributos sobresalientes y no sobresalientes. Si la cantidad de información relevante se incrementa, las decisiones crecen en complejidad, lo que demanda grandes esfuerzos cognitivos.

\section{Instrumentación contemporánea de los modelos de economía política en el desarrollo}

La teoría de la modernización sostiene que el desarrollo social y político de los pueblos ocurre en el cambio de racionalidad de una sociedad basada en los afectos a una asentada en los logros individuales. Esta teoría identificó etapas evolutivas del desarrollo de los pueblos.

Los siguientes veinticinco años al término de la segunda guerra mundial constituyeron una época de crecimiento sostenido (1945-1970) que dio lugar a dos décadas de resultados económicos, políticos y sociales dentro de una economía política cambiante, desde una profundización del modelo de desarrollo basado en el Estado de Bienestar a un modelo de desarrollo de corte más liberal. No menos importante entre estos resultados y predicciones fue la expectativa de que los factores demográficos responderían a la modernización y que, en particular, las tasas de fertilidad declinarían.

Las teorías de la modernización no predijeron bien otras consecuencias de esos procesos de difusión. La reacción a los errores predictivos del enfoque de la modernización no surgió primero de la sociología estadounidense, sino de su contraparte latinoamericana fuertemente influida por la economía política marxista. El marxismo es un acercamiento dialéctico al desarrollo de la humanidad, el cual señala a la lucha de clases como el motor 
del desarrollo capitalista hacia una sociedad socialista integrada por un sistema de producción, distribución y consumo formado por individuos en igualdad de condiciones en un Estado democrático. Con estas raíces teóricas firmemente plantadas en la economía política marxista, los trabajos acerca de la dependencia dejaron de lado todas las consideraciones de valores e ideas y culparon de la pobreza del tercer mundo a las corporaciones multinacionales y sus gobiernos protectores.

A partir de 1989, el Consenso de Washington articula un programa de economía política global y de reestructuración del sistema político basado en la gobernabilidad democrática, en torno al libre mercado como pensamiento único dominante. La estrategia de desarrollo de dicho Consenso como el único modelo para el desarrollo desde una economía de control de los estados-naciones fundado en la imposición de la democracia, el libre mercado y comercio en cada rincón del globo, aunada a la estrategia de guerra preventiva para la consolidación de supremacía militar, mantiene a Estados Unidos como la economía hegemónica del imperio.

La aplicación de este evangelio al desarrollo de los pueblos enfatiza el carácter de un sistema intelectual cerrado que supone la libertad comercial como la única real. El carácter normativo centrado en el racionalismo instrumental de las políticas económicas formuladas por el Consenso de Washington está orientado por procesos políticos de los participantes que tienen suficiente voluntad política para buscar la obtención de los mejores resultados del modelo de desarrollo de acuerdo con sus propios intereses estratégicos. Así, las diferencias de intereses de clase entre las naciones se obscurecen en categorías abstractas sólo identificables por su racionalidad económica instrumental.

La emergencia e instrumentalización de una nueva economía política en la transformación institucional del Estado-nación tiene impactos profundos en el desarrollo de los pueblos latinoamericanos. Por ejemplo, el cambio institucional de los servicios públicos con una orientación hacia la acción social centrado en los valores de la cultura cívica y en los valores del capital social es muy complejo, debido a la racionalidad instrumental del enfoque de la eficiencia económica que profundiza la política.

\section{Nuevo institucionalismo}

El neoinstitucionalismo económico relaciona en forma inextricable la economía y la política, ya que analiza las fallas de los mecanismos del Estado y sus ineficacias en el desarrollo. El papel de los valores es central al viejo institucionalismo, pero el neoinstitucionalismo se orienta más a los procesos cognitivos. El institucionalismo de la primera mitad del siglo XIX tenía una orientación descriptiva y usaba el razonamiento inductivo.

El neoinstitucionalismo que aglutina enfoques históricos, sociológicos y de la elección racional, surge a principios de la década pasada como un conjunto de reglas que determinan los procesos de la reforma institucional. Este conjunto de reglas emerge a partir de los

\section{DeSarrollo}


marcos de incentivos y restricciones impuestos a los comportamientos de los diferentes agentes y actores económicos, sociales y políticos para la formulación e implantación de políticas públicas y que tienen un impacto en los resultados medidos en términos de crecimiento y desarrollo. El nuevo institucionalismo se cimenta en un individualismo metodológico con base en el principio de que todos los resultados de las acciones humanas se explican por la acción individual, cuyas interacciones en las estructuras legitiman las instituciones. Este individualismo metodológico tiende a incentivar a los individuos en función de sus acciones.

El neoinstitucionalismo se fundamenta más en el razonamiento deductivo y se expresa en dos grandes enfoques. El primero se centra en la elección de las estructuras de mando/ gobierno (governance) de los actores privados en un determinado medio ambiente, el cual se convierte en el objeto de análisis económico. El segundo pone énfasis en el cambio institucional en función de los efectos que los diferentes medios ambientes institucionales tienen en el desempeño económico y en el desarrollo de las instituciones con el apoyo de modelos mentales compartidos e ideologías. El surgimiento espontáneo de las instituciones en las sociedades se explica por los modelos mentales compartidos e ideologías que determinan las percepciones de los actores en situaciones de interacción en las cuales la cultura y creencias conductuales tienen un papel relevante en los procesos de desarrollo, ahora en un entorno de procesos de globalización económica.

En ese sentido, la globalización no es un proceso unilineal que transforma las estructuras de mando de producción, distribución y consumo del nivel de las economías nacionales en una global, sino que también en forma paralela se desarrollan estructuras de mando privadas globales tales como la formación de sistemas de redes globales de valor agregado y quasi jerarquías para integrar a los emplazamientos locales en los procesos de producción, distribución y consumo de los mercados mundiales. Las estructuras de mando se convierten en híbridas en un continuo que va de la empresa en un extremo, al mercado en el otro. La creación de medios ambientes empresariales data de poco más de un siglo, pero ha adquirido carácter corporativo en los procesos de globalización económica. Sin embargo, las formas de mando privadas globales van más allá de la simple coordinación de mercados anónimos.

Entre el enfoque neoinstitucionalista y el de regulación democrática emerge el concepto de gobernabilidad como una relación existente entre los procesos de libre mercado y los de la democracia. El modelo de desarrollo con base en el mercado libre se soporta sobre una estructura institucional y jurídica, es decir, en un orden público económico concebido como el "conjunto de medidas adoptadas por los poderes públicos con el objeto de organizar las relaciones económicas y cuya función es la dirección y protección de la economía" (Streeter Prieto, 1985).

El neoinstitucionalismo pretende ordenar la esfera pública en un esquema de instituciones orientadas más al ordenamiento privado que aniquila toda pretensión de igualdad económica,

\section{DeSarrollo}


social y política, a partir del supuesto de que ya han sido obtenidas por el régimen democrático. Norberto Bobbio (1986) sostiene que "con una redundancia se puede definir el gobierno de la democracia como el gobierno del poder público en público", añadiendo que "el régimen democrático ha sido definido como el gobierno directo del pueblo o controlado por el pueblo". Resulta válido formular la pregunta acerca de cómo podría ser controlado si estuviese escondido. El poder del gobierno no puede ser arbitrario, sino que tiene que ser limitado cuando se trate de instrumentar la política económica de un modelo de desarrollo.

De acuerdo con Prats (2002), el mensaje del neoinstitucionalismo económico es una buena nueva para la democracia liberal en las condiciones actuales. Las instituciones necesarias para definir y garantizar los derechos individuales requeridos para el mayor y mejor desarrollo económico no sólo son compatibles, sino que son imprescindibles para disponer de una democracia duradera (Olson, 1993). Los componentes de la democracia liberal son el control del Estado y de sus decisiones y asignaciones en función del modelo de desarrollo que se fundamentan en las autoridades electas, un poder ejecutivo limitado por otras instituciones estatales autónomas, el respeto y reconocimiento de derechos a las minorías culturales, étnicas y religiosas, multiplicidad de canales de comunicación, expresión y representación de los intereses partidistas y de grupos, por mencionar algunos.

Para Olson (1993), el razonamiento sobre las implicaciones en el desarrollo es sencillo: dada una asignación eficiente de los derechos de propiedad (que no consolide, sino que impida las capturas de renta en el proceso político-económico), las personas y las organizaciones para ser económicamente eficientes necesitan un gobierno seguro que respete los derechos individuales y que genere un entorno de respeto a la propiedad ganada y dé cumplimiento de los contratos por medio de —en última instancia — una justicia imparcial.

El neoinstitucionalismo estudia los rasgos de las estructuras institucionales económicas que posibilitan el desarrollo de los pueblos y enfatiza las instituciones que definen el comportamiento de los actores frente a su medio social. El neoinstitucionalismo económico analiza las fallas de los mecanismos del Estado y sus deficiencias como mecanismo de gobernabilidad y coordinación que garantice los acuerdos y compromisos sobre la propiedad, base del desarrollo.

El nuevo institucionalismo atiende a los campos organizacionales como unidades de análisis. Los procesos institucionales pueden dar cierta estabilidad a dichos campos, aunque éstos siempre están evolucionando y no son estáticos, resolviendo mediante consenso negociado socialmente las diferencias de interpretación. Es cuestionable en la teoría económica neoinstitucional el hecho de que las instituciones disfuncionales que no alcanzan los niveles óptimos, permanezcan durante mucho tiempo y prolonguen el subdesarrollo, debido fundamentalmente a que tienen como causas mecanismos de autorefuerzo en procesos de dependencia. De acuerdo con la teoría neoinstitucional de la economía, el subdesarrollo

\section{DeSarrollo}


es resultado del fracaso del Estado para proporcionar las estructuras de mando necesarias para garantizar las instituciones que apuntalan el desarrollo de los pueblos. El neoinstitucionalismo recomienda un Estado fuerte pero limitado en sus funciones, las cuales serían sólo garantizar al mercado la posibilidad de ejercer su desempeño en el desarrollo sin obstaculizar su trabajo y protegerlo de injerencias ajenas (Estefanía, 2002).

De acuerdo con Burgos Silva (2002), el análisis económico neoinstitucionalista define la institucionalidad jurídica y el desarrollo económico, cuestiona el derecho como instrumento del desarrollo económico, reconoce las instituciones informales y promueve mecanismos institucionales considerados óptimos. La teoría neoinstitucionalista argumenta que la importancia de los marcos de referencia normativos y las reglas de comportamiento para guiar, constreñir, y crear poder en las organizaciones en las cuales se consideran, consisten de estructuras y actividades cognitivas, normativas y regulativas que dan significado al comportamiento social.

Una crítica al neoinstitucionalismo es que diseña arreglos institucionales con criterios óptimos de implantación en los países más desarrollados, los cuales son seriamente cuestionados por el camino de dependencia (path dependence) para ser adaptados en los países menos desarrollados.

\section{Nueva macroeconomía clásica (neoclásica)}

La nueva macroeconomía clásica, que tiene como premisas fundamentales los mercados libres y la optimación de los agentes que actúan de acuerdo con la hipótesis de las expectativas racionales, enfatiza la naturaleza racional de las expectativas y el problema de la inconsistencia del tiempo en la implantación de políticas, y describe un sistema económico con desarrollo estable.

A finales de los ochenta, el bloque soviético dio el empuje decisivo hacia la consolidación de la teoría neoclásica como la dominante, como el único acercamiento importante al desarrollo nacional, con las estrategias de crecimiento más centradas en el Estado, tales como las de los comunistas, ahora desacreditadas. El camino estaba libre para la expansión global del modelo de desarrollo impuesto por el capitalismo y, con ello, la hegemonía de la escuela teórica más orientada al mercado. La referencia espacial del desarrollo se ha movido del nivel nacional con el debilitamiento del Estado nación a los niveles supranacional y local con el fortalecimiento de los bloques regionales de integración y con la descentralización de funciones en los gobiernos locales.

La nueva macroeconomía clásica clama por reglas para controlar las políticas emanadas de la intervención del Estado en gran escala, que contribuyan a la efectividad de las políticas, a limitar la extensión de la interferencia gubernamental en la economía, y a rechazar, por lo tanto, todo tipo de intervencionismo del Estado en las actividades económicas. Un curso más apropiado de acción es examinar qué factores se pierden del

\section{Desaarrollo}


análisis neoclásico de los determinantes del desarrollo, de tal forma que los resultados puedan predecirse en forma más segura. Si bien este sistema económico se conforma de agentes racionales que tienen o actúan como si tuvieran un entendimiento claro de la economía, no hay una mención explícita de los factores institucionales que impliquen que éstos están cambiando.

Los economistas deben tener conocimiento de ello cuando elaboren sus teorías, aunque la nueva macroeconomía clásica ignora los factores institucionales del desarrollo y encuentra apoyo en la teoría de la elección pública (Gilbert and Michie, 1997). Ésta explica el comportamiento económico y político en función de la búsqueda de maximización de los beneficios de los individuos que realizan diferentes interacciones en un contexto institucional del desarrollo, el cual logra determinado equilibrio entre los principales agentes económicos y actores que realizan estrategias de negociación, competencia, formación de alianzas y coaliciones, entre otros. Esa concepción de la elección pública ha derivado en el fundamentalismo del mercado que considera que todo tipo de las interacciones humanas es reducible a simples transacciones de mercado.

Las elecciones privadas de los consumidores pueden ser más modeladas y manipuladas, no son autónomas e independientes, y son totalmente diferentes a las elecciones cívicas que hacen los ciudadanos. A pesar de esas consideraciones, la "lógica de las ganancias privadas" se ha impuesto sobre la "de los bienes públicos" en las cuales entran los mecanismos de competencia a generar y proveer los bienes públicos como privados, lo que conduce a situaciones similares a las mostradas en el "dilema del prisionero", como la peor solución. A tal grado que la teoría de la elección pública considera que el supuesto de la maximización de la utilidad racional debe extenderse a todas las instituciones, incluyendo el mismo gobierno, ya que éste está compuesto de individuos que también observan conductas en búsqueda de la maximización de los beneficios del desarrollo. Sin embargo, se invalida el soporte que la teoría de elección pública hace para la nueva macroeconomía clásica, la cual tiene un fuerte componente basado en el supuesto de las expectativas racionales que, en este caso, se ha universalizado.

Ciertamente, existen críticas graves al enfoque de la nueva macroeconomía clásica sobre la clarificación del mercado y su función central en el desarrollo, el cual se sale del terreno realista para caer en el campo nominalista; mientras que las hipótesis sobre las expectativas racionales tienen que ser consistentes con el modelo económico que cargan los individuos en sus mentes.

\section{Nueva economía política institucional}

La nueva economía política es un conjunto de enunciados teóricos que intenta explicar cómo se producen las restricciones que pesan sobre los sistemas financieros, a partir de la actividad que desarrollan los grupos de interés (Castro Reyes, 2002). La nueva economía

\section{DeSarrollo}


política se diferencia de la economía política que enfatiza el papel del gobierno en los procesos de desarrollo. Este enfoque es promovido por las instituciones financieras internacionales (IFI) por medio de las reformas del Estado, las cuales enfocan las transformaciones institucionales centradas en la promoción del desarrollo.

La nueva economía política se sustenta en la eliminación o relativización del supuesto de que los actores políticos actúan motivados por el bien común, al tiempo que los concibe motivados por una decisión racional (rational choice) que les permite obtener el máximo beneficio personal. Por lo tanto, los grupos de interés influyen en las regulaciones, de tal forma que a una mayor preeminencia del interés general, menor es el crecimiento y desarrollo nacional en el largo plazo, como en los casos de Alemania y Japón después de la segunda guerra mundial (Olson, 1965, 1986).

La nueva economía política institucional evita el holismo de la economía ortodoxa en la evaluación de los fenómenos sociales en las instituciones, como la cultura corporativa, entre otras, y en el análisis de las políticas mediante análisis institucional comparativo. La nueva economía política institucional se enfoca principalmente al desarrollo y crecimiento económicos y a la calidad de la gobernabilidad democrática.

Los promotores de la aplicación de los principios de la nueva economía política centrada en el libre mercado son los primeros que abandonan sus posiciones en tiempos de crisis económicas y retornan a buscar la protección del Estado-nación para extraer los recursos financieros necesarios para sortear sus problemas y eliminar los riesgos a sus inversiones. Resulta esencial, por ejemplo, que la falta de conformidad a las normas dictadas por la Organización Internacional del Trabajo (огт) pueda ser sancionado de modo que el trabajo no siga siendo una variable de ajuste sometida a los intereses financieros defendidos por las IFI y la Organización Mundial del Comercio (OMC).

La nueva economía política institucional se orienta a la consecución del desarrollo, el crecimiento económico y la gobernabilidad democrática. No obstante, la aplicación por los gobiernos de los países en desarrollo de una nueva economía política — que otorga un énfasis mayor a políticas económicas consistentes con el libre mercado y con la búsqueda de una gobernabilidad democrática - condujo a procesos regresivos de crecimiento económico y a crisis de gobernabilidad. El paradigma de la nueva economía institucional se interesa en las cualidades de coordinación de las instituciones. La coordinación está relacionada con el conjunto de instituciones capaces de producir expectativas que hacen posible a los individuos que no sigan los lineamientos de los planes centrales y que difieran coordinar, en sus metas, el éxito de los mismos.

En la nueva economía institucional, los aspectos políticos limitan los beneficios del comercio, como en las situaciones específicas de negociaciones asimétricas, debido a que prevalecen intereses creados que originan conflictos distributivos. En los análisis del término atribuido a Oliver Williamson (1975), la calidad de las instituciones tiene un papel 
determinante en la pobreza, considerando que tiene un costo la ejecución de las transacciones. Asimismo, dicha nueva economía da origen al término gobernabilidad en referencia a las instituciones que la sociedad debe poseer a fin de monitorear las reglas del juego. Además, deja en claro que las instituciones económicas, políticas y jurídicas son incompletas en cualquier sociedad y, por lo tanto, los costos de transacción no alcanzan los niveles deseados en el paradigma de la eficiencia. Las instituciones económicas más que el tipo de régimen político sustentan el desarrollo y el crecimiento económico.

A partir de los fundamentos teórico-metodológicos de las relaciones entre el desarrollo económico y las instituciones jurídicas que establece la nueva economía institucional, se superan las limitaciones del análisis del "movimiento del derecho y el desarrollo", y se establecen las bases para la construcción del estado de derecho promotor del desarrollo económico.

Con el apoyo instrumental teórico-metodológico de la nueva economía institucional, la teoría principal-agente y la transformación de capital social en político explican la formación de las políticas públicas y, por lo tanto, también determinan la acumulación del capital social de los diversos actores y su inversión en áreas diferentes, de acuerdo con su capacidad para identificar formas más eficientes de transformación de capital. El capital político se refiere a las actitudes y actividades que influencian al Estado. En la perspectiva privada, el capital político (instrumental) consiste en los recursos de los cuales un actor puede disponer y usar para influir en los procesos de formación de políticas y generar resultados de interés para él mismo. En la perspectiva pública, el capital político se refiere a "las variables estructurales del sistema político que influencian las posibilidades de los diversos actores políticos para acumular capital político instrumental, y que también terminan la efectividad de sus diversos tipos" (Birner y Wittmer, 2000).

\section{Implicaciones de la nueva economía politica para el desarrollo en las transformaciones institucionales del Estado-nación}

Los analistas y teóricos de los procesos de globalización se equivocan cuando sentencian la muerte prematura del Estado-nación. En realidad se aprecian fuertes procesos de transformación institucional de sus funciones en el desarrollo, desde el imperante marco de la nueva economía política. El Estado sigue siendo un actor de la globalización y de la economía política mundial importante, cuyas funciones son relevantes para la promoción y el control de la estructura hegemónica del sistema capitalista imperial. La estructura espacial de las diferentes unidades geográficas del Estado-nación se delimita territorialmente en función de sus fronteras físicas y geográficas y define las interrelaciones entre las diferentes entidades para la promoción del desarrollo y crecimiento económicos.

\section{DeSarrollo}


No obstante, el sistema capitalista transnacional tiene contradicciones internas que hacen que el Estado neoliberal impulsado por la nueva economía política atraviese por una crisis de gobernabilidad y legitimidad. Esto es debido a que los procesos de globalización debilitan la integración económica interna, con lo cual se pierde la capacidad para armonizar los intereses sociales conflictivos y, por tanto, para mantener la cohesión social de los estados nacionales. Más aún, se está demostrando que el libre comercio en el esquema de la globalización económica no mejora necesariamente las condiciones de competitividad en aquellos países donde éstas no existen, regularmente los países pobres. Así, el Estado, el mercado y la comunidad son mecanismos de coordinación y gobernabilidad imperfectos, que presentan diferentes ventajas y desventajas, pero que se complementan.

La reforma del Estado modifica su capacidad reguladora y su papel de protección y asistencia a la comunidad, en beneficio de las instituciones del mercado. La reforma del Estado basada en el modelo racional normativo weberiano se caracterizó por la racionalización legalista del Estado, que fortaleció la administración burocrática de estructuras verticales y una cultura patrimonialista y clientelar, la cual se realizó desde los años cincuenta y hasta los ochenta. Así, el perfil de las burocracias latinoamericanas se aleja del modelo racional de burocracia de Weber para ajustarse a las necesidades del modelo de Estado social democrático. Pero este viejo modelo de gestión pública burocrática basada en una racionalidad normativa ha cedido paso a un modelo de gestión orientado por una racionalidad tecnocrática.

La reforma administrativa de los setenta se orientó a la búsqueda de la racionalidad instrumental y la neutralidad política. Los procesos de modernización implican el cálculo y control de los procesos sociales y naturales que corresponden al desarrollo de la racionalidad instrumental, la cual se contrapone a la normativa, que tiene que ver con la modernidad orientada a la autonomía moral y a la autodeterminación política. En los ochenta se transitó de la administración a la gerencia pública en la búsqueda de las organizaciones gubernamentales más eficientes y eficaces mediante el uso de racionalidades instrumentales. Se desarrolló el concepto de políticas públicas orientadas por el Consenso de Washington y se profundizó en los procesos de formulación e implantación.

De esa forma, el crecimiento económico y el desarrollo de un país se explican por sus instituciones. Mediante un nuevo diseño institucional sustentado en cambios constitucionales, se amplia la distribución del poder a las organizaciones sociales y privadas. Actualmente, la reforma del Estado sustentada por la nueva economía política enfatiza las reformas institucionales que fortalecen la gobernabilidad con base en un sistema democrático y de libre mercado. Las reformas institucionales de largo alcance, también llamadas reformas de segunda generación, tratan de justificar su orientación para alcanzar mayor eficiencia económica y mejores niveles de desarrollo y equidad social. 
Con el supuesto del secuenciamiento, para entrar a la reforma de la nueva gerencia que promueve una mayor flexibilidad en el empleo público, era necesario haber cubierto completamente la etapa de los servicios públicos, que implicó el servicio civil en los administradores de carrera. La reforma del aparato burocrático administrativo del Estado está orientada al nuevo gerencialismo, a los procesos de democratización, y hacia los consumidores que en mercados competitivos realizan elecciones racionales, lo que termina reduciendo al ciudadano en un consumidor.

El Estado sigue siendo un actor de la globalidad y de la economía política mundial importante, cuyas funciones son relevantes para la promoción y el control de la estructura hegemónica del sistema capitalista imperial. La regulación mundial no puede ser definida únicamente en términos institucionales, ya que las cuestiones de derecho tienen su importancia. Es necesario que las IFI se sometan al derecho internacional, especialmente a los protocolos y a los acuerdos que han suscrito la mayoría de los estados integrantes. Contrariamente a la retórica de los empresarios y la clase capitalista transnacional, el Estado seguirá desempeñando un papel importante en el desarrollo, porque requiere del fortalecimiento en sus funciones de regulación, cuya finalidad es eliminar los riesgos que pueden atentar contra sus inversiones y garantizar la reproducción y el acrecentamiento de sus capitales.

\section{Bibliografía}

Appelbaum, Richard y Jeffrey Henderson, "The hinge of history: Turbulence and transformation in the world economy", en Competition \& Change, vol. 1, núm. 1, 1995.

Birner, Regina y Heidi Wittmer, "Converting social capital into political capital. How do local communities gain political influence? A theorethical approach and empirical evidence from Thailand and Colombia", Paper submitted to the $8^{\text {th }}$ Biennal Conference of the International Association for the Study of Common Property, IASCP, 2000.

Bobbio, Norberto, El futuro de la democracia, México, FCE, 1986.

Burgos Silva, Germán, "Estado de derecho y desarrollo económico: aportes y limitaciones de los análisis neoinstitucionales", en Revista Instituciones y Desarrollo, núms. 12-13, Barcelona, Institut Internacional de Governabilitat de Catalunya, 2002.

Castro Reyes, Alexander, "Extracción de rentas en la banca estatal costarricense. El caso del Banco Anglo Costarricense", en Delaware Review of
Latin American Studies, vol. 3, núm. 1, febrero, 2002.

Coase, R., "The nature of the firm", en Económica, 4, 1937.

Coleman, James, "Social capital in the creation of human capital", en American Journal of Sociology, Supplement, vol. 95, Chicago, The University of Chicago, 1988.

Estefanía, Joaquín, "La enfermedad moral del capitalismo", en Granito de arena, agosto $7 \mathrm{de}$ 2002, Argentina, 2002.

Giddens, A., The constitution of society, Los Angeles, University of California Press, 1984.

Gilbert, Evan y Jonathan Michie, "New classical macroeconomic theory and fiscal rules: some methodological problems", en Contributions to Political Economy 16, 1997.

Habermas, J., Faktizät und geltung-Beiträge zur Diskurstheorie des Reshcts und des demokratischen rechtsstaats, Darmstadt: Wissenschaftliche Buchgesellschaft, 1992

Hermalin, E. Benjamin, Economics \& corporate culture, Draft, Berkeley, Cornell University and University of California, 1999.

\section{Desarrollo}


Olson, Mancur, "Dictatorship, Democracy and Development", en American Political Science Review, vol. 87, núm. 3, septiembre, 1993.

Olson, Mancar, Auge y decadencia de las naciones, Barcelona, Ariel, 1986.

, The logia of collective action, Cambridge, Harvard University Press, 1965.

Prats, Joan, Instituciones y desarrollo en América Latina ¿Un rol para la ética?, Instituto Internacional de Gobernabilidad, 17 de septiembre de 2002.

Polanyi Karl, Arensberg Conrad y Pearson Harry (editores), Les systémes économiques dans l'économie, París, Librairie Larousse, 1975.
Simon, Herbert A., "A behavioral model of rational choice," en Quarterly Journal of Economics, 69, febrero, 1955.

Streeter, Prieto, J., Materiales de trabajo sobre el orden público económico, mimeo, Facultad de Derecho, Universidad de Chile, 1985.

Weber, M., Economy and society, (G. Roth y C. Wittich, editores), Berkeley, University of California Press, 1978.

Williamson, O.E., Markets and Hierarchies: Analysis and Antitrust Implications, Nueva York, Free Press, 1975.

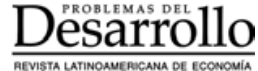

